\title{
Asiaticoside increases aquaporin-3 protein expression in the cytoplasm of normal human epidermal keratinocytes
}

\author{
Linda Yulianti Wijayadi and Hari Darmawan
}

\begin{abstract}
\section{INTRODUCTION}

Skin hydration decreases with aging. Aquaporin-3 (AQP3) is a major protein that plays a role in skin hydration, therefore it is a novel target for skin moisturizing treatment. Retinoic acid (RA) as a well-known active agent in antiaging treatment increases AQP3 expression, but frequently causes harmful side effects. Asiaticoside, a saponin compound isolated from Centella asiatica (CA) is also known as an antiaging cosmetic and plays a role in wound healing. The aim of this study was to evaluate and compare the effect of asiaticoside isolated from CA and the effect of RA on the AQP3 expression in normal human epidermal keratinocytes (NHEKs).
\end{abstract}

\section{METHODS}

An experimental laboratory study was performed using primary NHEKs that were derived from the foreskin of a boy. AQP3 expression in NHEKs was examined in vitro after the cells were incubated for 24 hours with asiaticoside or with RA at several concentrations. The AQP3 expression was evaluated by immunocytochemistry and quantitatively analyzed by Image-J software. Independent t-test and one-way ANOVA were used to analyze the data, followed by post-hoc Tukey test.

\section{RESULTS}

There was an increasing trend of AQP3 expression upon exposure to asiaticoside at all concentrations compared to the control group. However, RA exposure seemed to induce a higher level of AQP3 expression. Asiaticoside effected a lower increase in AQP3 expression in NHEKs than did RA ( $\mathrm{p}=0.042)$. Optimal results were achieved at $1 \mathrm{mg} / \mathrm{mL}$ concentration of asiaticoside.

\section{CONCLUSIONS}

Asiaticoside isolated from CA can enhance the AQP3 expression in NHEKs. Therefore it can be used as an active ingredient in cosmetic moisturizer formulation for dry skin treatment.

Keywords Centella asiatica, asiaticoside, keratinocytes, aquaporin-3, retinoic acid
*Department of Dermatovenereology, Faculty of Medicine, Tarumanagara University

Correspondence:

Dr. dr. Linda Yulianti Wijayadi,

Sp.KK., FINSDV

Department of Dermatovenereology

Faculty of Medicine,

Tarumanagara University

Jl. Letjen S. Parman No. 1

Jakarta Barat 11440

Email:

lindajuliantiwijayadi@gmail.com

Univ Med 2017;36:25-33

DOI: $10.18051 /$ UnivMed.2017.v36.25-33 pISSN: 1907-3062 / eISSN: 2407-2230

Received October 17, 2016

Accepted for publication April 7, 2017

This open access article is distributed under a Creative Commons Attribution-Non Commercial-Share Alike 4.0 International License 


\section{INTRODUCTION}

Skin aging is a complex process controlled by genetic determinants (intrinsic aging) and under the influence of external factors (extrinsic aging). ${ }^{(1,2)}$ The aging process reduces skin surface hydration, which then results in dry, dull, coarse and saggy skin. Other visible signs of aging include pigmentation and the appearance of benign skin tumors. Moreover, the epidermis becomes thinner with age and develops wrinkles as a result.

The aquaporins (AQPs) are a family of small transmembrane proteins that facilitate osmotically driven water transport. To date, 13 AQPs (AQP 0-12) have been cloned from humans and are categorized into distinct subgroups in terms of their amino acid sequence and molecular functions. ${ }^{(3)}$

Aquaporin-3 (AQP3) as a water and glycerol channel is the key factor in the skin hydration mechanism as well as in keratinocyte proliferation and differentiation. ${ }^{(4,5)}$ However, AQP3 expression in normal human epidermal keratinocytes (NHEKs) decreases along with the aging process. Natural active compounds that can stimulate AQP3 expression would be effective as hydrating agents or moisturizers in anti-aging cosmetics. ${ }^{(6)}$ Therefore, AQP3 is a key protein target for future anti-aging treatment, in order to improve hydration, texture, and quality of the skin surface. ${ }^{(6)}$

Cosmeceutical anti-aging formulations contain active ingredients to achieve local therapeutical effects, which should not have harmful local and systemic side effects. ${ }^{(7)}$ The well known anti-aging ingredients, retinoic acid (RA) and its derivatives, have harmful side effects by irritating the skin and causing dry, flaky skin, which is sensitive to light. ${ }^{(8)}$ Thus, it is necessary to develop innovative cosmeceutical anti-aging formulations with active ingredients which are effective, stable, safe and nontoxic. Additionally, these ingredients should be compatible with other active ingredients and be delivered efficiently to the target cells. ${ }^{(9)}$ A study found that all-trans retinoic acid attenuates ultraviolet radiation-induced down-regulation of aquaporin-3 and water permeability in human keratinocytes. ${ }^{(10)}$ Another study showed that trans-zeatin attenuates ultraviolet induced downregulation of aquaporin-3 in cultured human skin keratinocytes. ${ }^{(11)}$

Indonesian natural herbs promise a great potential for herbal cosmetics. Centella asiatica (CA) (synonym: Hydrocotyle asiatica), commonly known as gotu kola, is often found in Indonesia and has been used for various medicinal purposes such as wound healing, treatment of asthma, ulcers, leprosy, lupus erythematosus, psoriasis, venous disorders, and cancer since 1000 years ago. ${ }^{(12-14)}$ The biologically active ingredients in $\mathrm{CA}$ are triterpenes, namely asiatic acid, madecassic acid, asiaticoside and madecassoside. ${ }^{(13,14)}$

Asiaticoside isolated from CA induces human dermal fibroblast (HDF) proliferation and type I and III collagen synthesis in a time- and dose-dependent pattern. ${ }^{(15)}$ Therefore, asiaticoside as an active component isolated from CA can improve wound healing. ${ }^{(16)}$ Asiaticoside displays the highest activity and has been widely used in wound healing treatment and anti-aging cosmetics, hence it also can be used as active mosturizing agent. ${ }^{(15)}$ The study conducted by Julianti et al. ${ }^{(17)}$ showed that CA ethanolic extract encapsulated into chitosan nanoparticles can be used as moisturizer for antiaging activity by inducing AQP3 expression in NHEKs. Unfortunately there is a lack of research exploring the efficacy of asiaticoside as an active agent in CA that can increase AQP3 expression in NHEKs. ${ }^{(17)}$

Asiaticoside possesses interesting wound healing and angiogenic activities that are employed to stimulate tissue regeneration in wound healing applications. One study attempted to develop a chitosan-aluminum monostearate (Alst) composite sponge containing asiaticoside for use as an absorbent medical dressing in chronic wounds. The study found that asiaticoside and asiaticoside-containing dressings 
exhibited dose-dependent angiogenic activity in the chick-chorioallantoic membrane model. Therefore chitosan-aluminum monostearate composite sponge dressings containing asiaticoside may be of benefit for wound healing and angiogenesis promotion in chronic wounds. ${ }^{(18)}$

There has been no studies on the expression of AQP3 in NHEKs after treatment with asiaticoside as compared with that of RA. The aim of this study was to evaluate and compare the effect of asiaticoside isolated from CA and that of RA on the expression of AQP3 in NHEKs.

\section{METHODS}

\section{Research design}

An experimental laboratory study was conducted in the Eijkman Institute, Jakarta, from January to April 2015.

\section{Treatment}

RA was purchased from BASF, Germany, and chitosan with a deacetylation degree of $>75 \%$ from Sigma-Aldrich, USA. Asiaticoside was prepared in the Center for Pharmaceutical and Medical Technology, Agency for the Assessment and Application of Technology, Center for Research in Science and Technology (BPPT PUSPIPTEK), Serpong. RA and asiaticoside in step wise dilutions from $1 \mathrm{mg} / \mathrm{mL}, 0.5 \mathrm{mg} / \mathrm{mL}$, to $0.25 \mathrm{mg} / \mathrm{mL}$ were used to determine AQP3 expression by immunocytochemistry.

\section{Tissue samples and cell culture}

Primary NHEKs were derived from the foreskin of a boy and cultured in Roswell Park Memorial Institute (RPMI) medium supplemented with $10 \%$ fetal bovine serum (FBS) and 1\% penicillin-streptomycin. NHEK cell cultures were prepared in the integrated laboratory of Yarsi University, Jakarta.

\section{Immunocytochemistry}

Immunocytochemistry (ICC) was performed at Eijkman Institute, Jakarta. ICC is a specific cellular protein detection technique using a specific antibody $(\mathrm{Ab})$ to recognize cellular surface antigens. Immunochemical staining was done using anti-aquaporin3 antibody Ab125219. Expression of AQP3 in NHEKs was then quantitatively analyzed by ImageJ software.

\section{Statistical analysis}

Data obtained in this study are presented as images, tables or graphs. To assess for significance across the different treatment groups, independent t-test and one-way ANOVA were used, followed by post-hoc Tukey test. The significance level was set at $p<0.05$ using SPSS software version 21 .

\section{RESULTS}

\section{AQP3 protein expression in keratinocytes following 24 hours exposure to asiaticocide}

In order to examine the expression of AQP3 protein, an immunocytochemical test with antiaquaporin3 antibody (Ab125219) was done and visualized with the light microscope to obtain qualitative data. In this study we used three different concentrations of asiaticoside, i.e. 0.25, 0.5 , and $1 \mathrm{mg} / \mathrm{mL}$. Three different RA concentrations, namely $0.25,0.5$, and $1 \mathrm{mg} / \mathrm{mL}$, which are commonly used in topical preparations, were applied as controls in this study.

The study indicated an increased expression of AQP3 protein in keratinocytes upon exposure for 24 hours to asiaticoside at three different concentrations, namely $0.25 \mathrm{mg} / \mathrm{mL}, 0.5$ $\mathrm{mg} / \mathrm{mL}$, and $1 \mathrm{mg} / \mathrm{mL}$. The expression of AQP3 protein as indicated qualitatively increased linearly in relation with the concentrations of asiaticoside (Figure 1).

We found an increasing expression of AQP3 protein in NHEKs following 24 hours exposure to RA at three different concentrations $(0.25 \mathrm{mg} /$ $\mathrm{mL}, 0.5 \mathrm{mg} / \mathrm{mL}$, and $1 \mathrm{mg} / \mathrm{mL}$ ). AQP3 protein expression increased proportionally with RA concentration (Figure 2). 


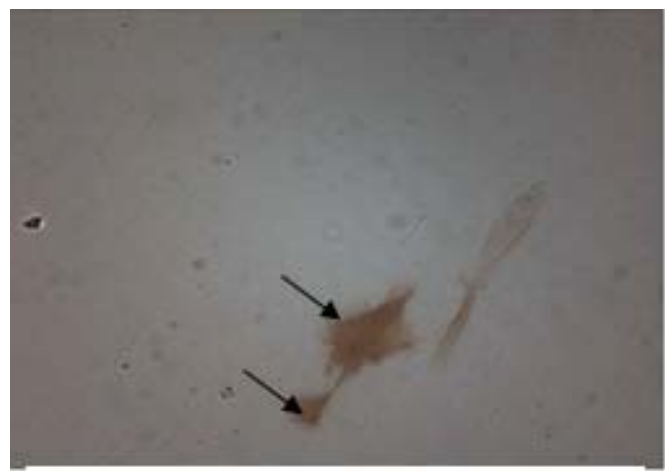

Without Treatment

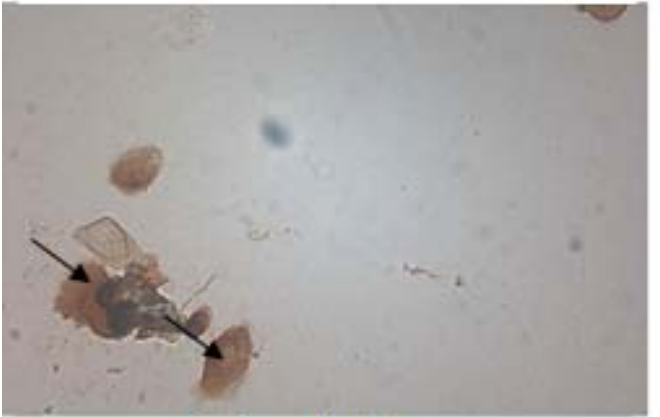

\section{$0.5 \mathrm{mg} / \mathrm{mL}$}

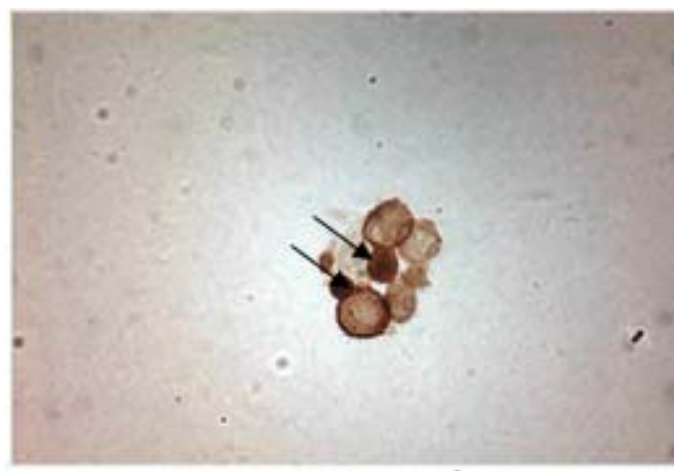

$0.25 \mathrm{mg} / \mathrm{mL}$

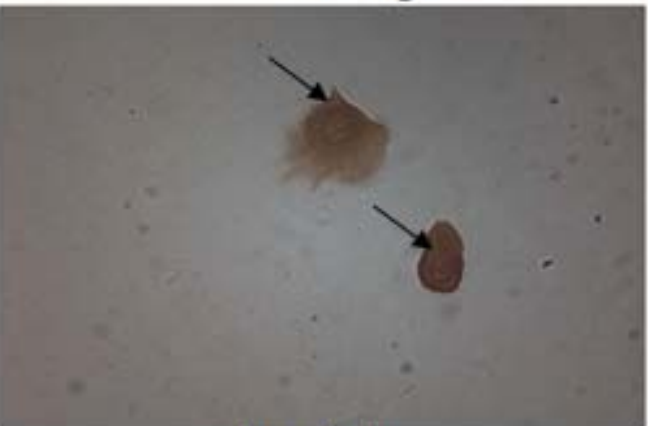

$1 \mathrm{mg} / \mathrm{mL}$

Figure 1. AQP3 protein expression (brown colour, pointed by arrows) in NHEKs: (a) without treatment (control); and after $24 \mathrm{~h}$ exposure to asiaticoside at concentrations of: (b) $0.25 \mathrm{mg} / \mathrm{mL}$; (c) $0.5 \mathrm{mg} / \mathrm{mL}$; and (d) $1 \mathrm{mg} / \mathrm{mL}$, at 400x magnification. Immunocytochemical staining with anti-aquaporin3 antibody ab125219

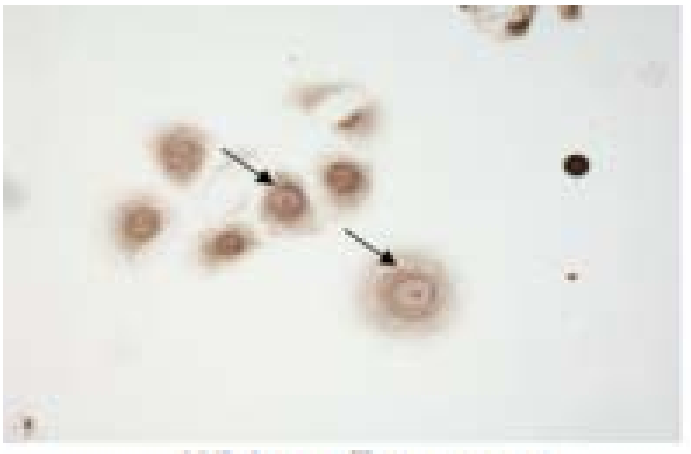

Without Treatment

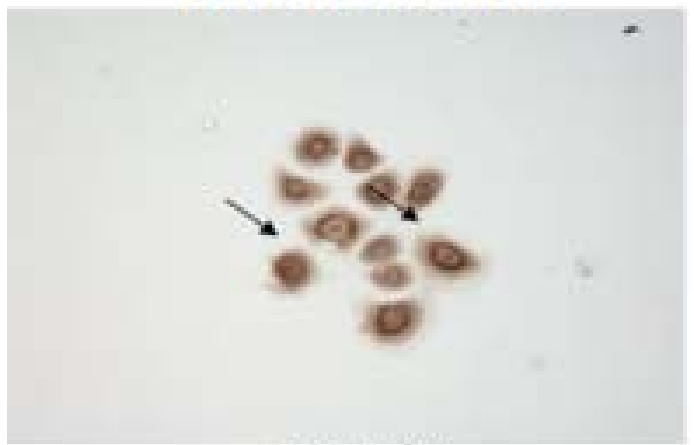

$0.5 \mathrm{mg} / \mathrm{mL}$

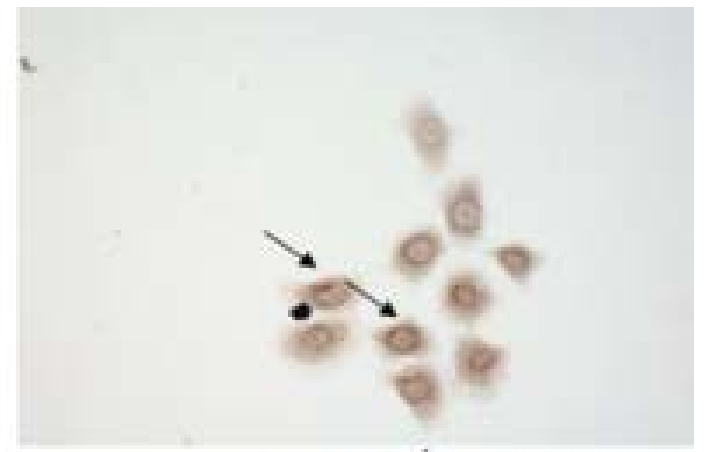

$0.25 \mathrm{mg} / \mathrm{mL}$

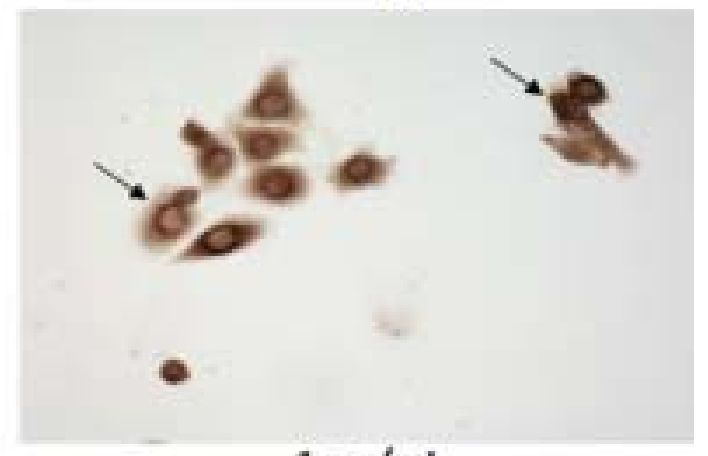

$1 \mathrm{mg} / \mathrm{mL}$

Figure 2. AQP3 protein expression (brown colour, pointed by arrows) in NHEKs: (a) without treatment (control); and after $24 \mathrm{~h}$ exposure to RA at concentrations of: (b) $0.25 \mathrm{mg} / \mathrm{mL}$; (c) $0.5 \mathrm{mg} / \mathrm{mL}$; and (d) $1 \mathrm{mg} / \mathrm{mL}$, at 400x magnification. Immunocytochemical staining with anti-aquaporin3 antibody ab125219 
Table 1. AQP3 expression after 24 hours exposure by treatment groups

\begin{tabular}{lcccc}
\hline \multirow{2}{*}{ Concentration } & \multicolumn{3}{c}{ Group } & \multirow{2}{*}{ p } \\
\cline { 2 - 4 } & Asiaticoside & RA & Control & 0.020 \\
\hline $0.25 \mathrm{mg} / \mathrm{mL}$ & $10,611,680.05$ & $15,877,259.69$ & $9,317,580.44$ & 0.006 \\
$0.5 \mathrm{mg} / \mathrm{mL}$ & $12,661,966.22$ & $22,113,143.61$ & $9,317,580.44$ & 0.042 \\
$1 \mathrm{mg} / \mathrm{mL}$ & $15,064,493.31$ & $24,913,142.79$ & $9,317,580.44$ & 0.042 \\
\hline
\end{tabular}

Note: One way ANOVA between control, asiaticoside and RA is statistically significant at all concentrations $(\mathrm{p}<0.05)$; Post hoc Tukey analysis between RA $(1 \mathrm{mg} / \mathrm{mL})$ and control is statistically significant $(\mathrm{p}=0.010)$; Post hoc Tukey analysis between RA $(0.5 \mathrm{mg} / \mathrm{mL})$ and asiaticoside $(0.5 \mathrm{mg} / \mathrm{mL})$ is statistically significant $(\mathrm{p}=0.024)$; Post hoc Tukey analysis between asiaticoside $(1 \mathrm{mg} / \mathrm{mL})$ and control is statistically significant $(\mathrm{p}=0.037)$

Comparison of AQP3 protein expression in NHEKs following 24 hours exposure to asiaticoside and RA using ImageJ software

The qualitative results from the immunocytochemical analysis in the form of images were analyzed using the ImageJ program to obtain quantitative results for statistical analysis.

Following previous qualitative analysis, AQP3 expression was found to be increased with both increasing asiaticoside and RA concentration. Qualitative analysis of different color densities using ImageJ program showed that expression of AQP3 was significantly highest on RA exposure as compared to asiaticoside $(1 \mathrm{mg} / \mathrm{mL})$ (Table 1$)$.

There was an increasing trend of AQP3 expression upon exposure to asiaticoside at all concentrations compared to the control (no exposure) group. However, RA exposure seemed to induce a higher level of AQP3 expression (Figure 3).

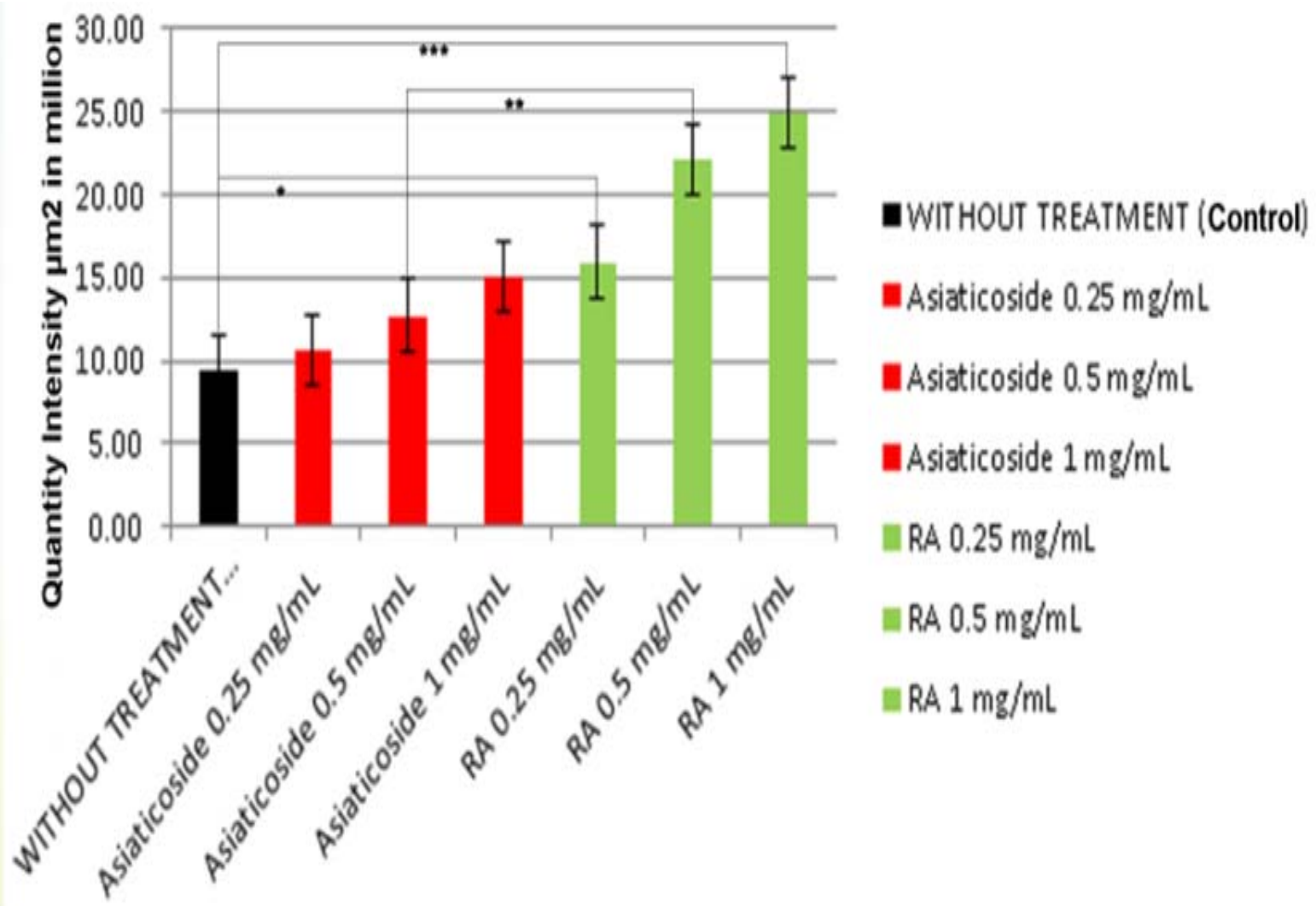

Figure 3. Mean AQP3 expression in keratinocytes following 24 hours exposure to asiaticoside and RA using ImageJ program 


\section{DISCUSSION}

After 24 hours of incubation with three different asiaticoside concentrations $(0.25 \mathrm{mg} /$ $\mathrm{mL}, 0.5 \mathrm{mg} / \mathrm{mL}$, and $1 \mathrm{mg} / \mathrm{mL}$ ), an increased expression of AQP3 protein in the cytoplasm of NHEKs was found. However, the expression of AQP3 protein was reduced upon exposure to the highest asiaticoside concentration $(1 \mathrm{mg} / \mathrm{mL})$. This result shows that the relation between expression of AQP3 and asiaticoside concentration is linear within a certain range. Other studies showed that concentration and exposure time were important factors in determining the expression of AQP3 protein. Pereda et al. ${ }^{(19)}$ showed that green Coffea arabica seed extract may increase AQP3 protein expression in normal human epidermis. There was a 6.5 fold increase in AQP3 mRNA expression compared to negative controls following a 3-6 hours incubation with the optimal concentration of $25 \mathrm{mg} / \mathrm{mL}$. Another study done by Pereda et al. ${ }^{(20)}$ regarding the induction of AQP3 protein with Piptadenia colubrina extract (10 and $20 \mathrm{mg} / \mathrm{mL}$ ) in human skin cell cultures showed a statistically significant increase in AQP3 mRNA expression, analyzed using realtime PCR. AQP3 started to increase after 2 hours and peaked at 6 hours, then further declined after 24 hours.

In our study, the evaluation of increased AQP3 protein expression using immunocytochemistry was done after 24 hours of exposure to asiaticoside, as we hoped that the topical treatment can eventually be done once daily with its effect remaining up to 24 hours. This concept is similar to those of previous studies done by Pereda et al. ${ }^{(20)}$ and Perez et al. ${ }^{(21)}$ The latter evaluated the effect of $3 \%$ Aquaxyl ${ }^{\mathrm{TM}}$ solution on AQP3 expression in keratinocytes after 24 hours exposure, because a moisturizing cream should have a long lasting effect. AQP3 protein, as a water and glycerol channel, acts to transport water and glycerol to the skin, thus holding an important aspect in skin hydration. ${ }^{(4,22)}$ A further study done by Li et al. ${ }^{(23)}$ regarding the reduced expression of AQP3 in keratinocytes and its relation to age indicates that AQP3 holds an important aspect in maintaining skin hydration and is reduced following an aging process. ${ }^{(24,25)}$ AQP3 plays an important role in wound healing, since it acts as a water channel that helps the migration of NHEKs, while acting further to transport glycerol which may increase the proliferation and differentiation rate of NHEKs. ${ }^{(26)}$

A previous study done by Ji et al. ${ }^{(11)}$ showed that trans-zeatin increased AQP3 protein expression in NHEKs, depending on its concentration and time of exposure, with the most optimal condition at 48 hours and $80 \mathrm{~mol}$ concentration. Nowadays, there are many cosmetic moisturizers that are formulated with some active agent and claimed to increase the expression of AQP3 protein in NHEKs of the epidermis. The fact of increased expression of AQP3 is crucial in increasing resistance, skin barrier integrity, quality of the skin surface and in improving skin hydration. Asiaticoside is one of the active components in CA. Our in silico research has previously showed that asiaticoside has the highest bond energy in comparison to the other active ingredients in CA (asiatic acid, madecassic acid and madecassoside), at the same binding site at 234 alanine in AQP3. ${ }^{(27)}$

The results of the present study indicated that AQP3 protein expression increased in NHEKs after 24 hours treatment with asiaticoside at concentrations of $0.25,0.5$ and 1 $\mathrm{mg} / \mathrm{mL}$. Aquaporin-3 expression was 1.5 times greater as compared with negative controls, and the optimal concentration was found at $1 \mathrm{mg} /$ $\mathrm{mL}$. These results indicate that asiaticoside can be used as a moisturizing cosmetic active ingredient to improve skin hydration.

After NHEKs were incubated with all-trans retinoic acid (ATRA) for 24, 48, and 72 hours, the compound stimulated the entry of glycerol and increased expression of AQP3 followed by an increase in biological activity in human skin, such as the proliferation and differentiation of cells in the basal layer of the epidermis. ${ }^{(28)}$ 
Retinol and RA are commonly used in antiaging cosmetics. Retinol as one of the active ingredients can enhance in vivo repair of skin damage due to exposure to ultraviolet light ("photoaging"). Topical application of retinol and RA achieves the treatment of "photoaging" by improving wrinkles, dry skin and delayed wound healing, but often causes side effects, such as skin irritation and dryness. ${ }^{(8,9)}$

The effects of ultraviolet light causes a down regulation in AQP3 expression resulting in water permeability decrease and in reduced NHEK migration and proliferation, which inhibits wound healing. This negative effect is reduced by ATRA therapy. These findings support the role of AQP3 in dehydrated skin due to sun exposure. ${ }^{(10)}$

In our study, the expression of AQP3 in NHEKs increased after 24 hours treatment with $\mathrm{RA}$ at concentrations of $0.25,0.5$, and $1 \mathrm{mg} /$ $\mathrm{mL}$. The intensity of AQP3 protein expression in NHEKs is directly proportional to the increase in concentration. ATRA increases AQP3 expression in NHEKs through retinoic acid receptor gamma (RAR- $\gamma$ ). This is consistent with our finding that RA increased AQP3 exspression in NHEKs at concentrations of $0.25,0.5$ and 1 $\mathrm{mg} / \mathrm{mL}$.

The quantitative analysis based on color density using ImageJ showed that exposure of NHEKs to asiaticoside concentrations of 0.25 and $0.5 \mathrm{mg} / \mathrm{mL}$ induces a slight increase in expression of AQP3 proteins. Meanwhile, a significant increase in AQP3 protein expression was seen at $1 \mathrm{mg} / \mathrm{mL}$ after exposure to RA at all three test concentrations, the AQP3 expression increasing to a greater extent as shown in Figure 3.

In the present study one-way ANOVA was used to determine significant differences in AQP3 expression in NHEKs after 24 hours exposure to asiaticoside, RA and in NHEKs without treatment at all test concentrations. The analysis was continued with the post hoc Tukey test, demonstrating significant differences at a concentration of $0.25 \mathrm{mg} / \mathrm{mL}$ between the RA and control groups, at a concentration of $0.5 \mathrm{mg} /$ $\mathrm{mL}$ between RA and controls, also between asiaticoside and controls, and finally, at a concentration of $1 \mathrm{mg} / \mathrm{mL}$ between controls and RA.

Currently many research studies are being performed to investigate active compounds with the ability to increase AQP3 expression, thereby increasing the skin hydration endogenously. Included in this list of active compounds are those from Coffea Arabica, ${ }^{(17)}$ Piptadenia colubrina, ${ }^{(18)}$ and Ajuga turkestanica. ${ }^{(19)}$

From research on the induction of AQP3 by Piptadenia colubrina extract at concentrations of 10 and $20 \mathrm{mg} / \mathrm{mL}$ in cultured human skin cells it was found that the extract significantly increased the AQP3 mRNA expression as analyzed by real time- polymerase chain reaction (RT-PCR). ${ }^{(18)}$ AQP3 began to increase after 2 hours, reached its peak at 6 hours, and decreased after 24 hours. Immunohistochemical examination showed increased expression of AQP3 in the membrane of NHEKs after exposure to the Piptadenia colubrina extract at a concentration of $10 \mathrm{mg} /$ $\mathrm{mL}$ for 24 hours compared to the control group without treatment. ${ }^{(18)}$

In another study by Pereda et al. ${ }^{(20)}$ an extract of green Coffea arabica seed showed increased AQP3 expression in the normal epidermal layer of human skin. NHEKs were incubated for 3-6 hours with the optimal concentration of $25 \mathrm{mg} / \mathrm{mL}$. AQP $3 \mathrm{mRNA}$ achieved relative expression levels of up to 6.5 times than the negative controls.

Our study indicates that asiaticoside can increase the expression of AQP3 at all concentrations tested, but at a lower level than RA. Therefore, we may infer that asiaticoside at these concentrations does not cause dryness of the skin, which is a side effect of RA (due to over expression of AQP3).

In our study, we only determined the AQP3 expression in NHEKs at a single point in time after 24 hours exposure to asiaticoside, so it was not exactly known when AQP3 expression began 
to increase and decrease in NHEKs. Asiaticoside can be used as an active ingredient in cosmetic moisturizers but still needs clinical trials to further determine its effectiveness and safety.

\section{CONCLUSIONS}

Asiaticoside increases AQP3 protein expression in NHEKs at concentrations $0.25,0.5$ and $1 \mathrm{mg} / \mathrm{mL}$. The increase in AQP3 expression is directly proportional to the concentration. Therefore asiaticoside can be used as an active ingredient in cosmetic moisturizers, to regulate skin hydration by increasing AQP3 expression.

\section{CONFLICT OF INTEREST}

The authors have no conflict of interest.

\section{ACKNOWLEDGEMENT}

The authors wish thank Intan Razari and Dani for laboratory assistance, dr. Indra Kusuma for NHEK cell cultures and Dr. Prasetyawan Yunianto for providing asiaticoside from the Agency for the Assessment and Application of Technology (Badan Pengkajian dan Penerapan Teknologi).

\section{CONTRIBUTION}

LYW contributed to drafting the manuscript and the design of the study. LYW and HD contributes to data collection, analysis and interpretation. LYW contributed revising manuscript for critically important content. All authors read and approved the final manuscript.

\section{REFERENCES}

1. Rhein L. Aging skin-General considerations. In: Rhein L, Fluhr JW, editors. Aging skin: current and future theurapeutic strategies. USA: Allured Books; 2010.p.8-11.

2. Rabe JH, Mamelak AJ, McElgunn PJ, et al. Photoaging: mechanisms and repair. J Am Acad Dermatol 2006;55:1-19.
3. Sugiyama Y, Yamazaki K, Kusaka-Kikushima A, et al. Analysis of aquaporin 9 expression in human epidermis and cultured keratinocytes. FEBS Open Bio 2014;4:611-6.

4. Boury-Jamot M, Sougrat R, Tailhardat M, et al. Expression and function of aquaporins in human skin: is aquaporin-3 just a glycerol transporter? Biochim Biophys Acta 2006;1758:1034-42.

5. Draelos Z. Aquaporins: an introduction to a key factor in the mechanism of skin hydration. J Clin Aesthet Dermatol 2012;5:53-6.

6. Verkman AS. A cautionary note on cosmetics containing ingredients that increase aquaporin 3 expression. Exp Dermatol 2008;17:871-2.

7. Baumann L. Skin ageing and its treatment. J Pathol 2007;211:241-51.

8. Rittie L, Fisher GJ, Voorhess JJ. Retinoid therapy for photoaging. In: Gilchrest B, Krutmann J,editors. Skin aging. Berlin: Springer;2006. p.143-56.

9. Rawling AV. Retinoids and retinoic acid treatment of skin aging. In: Rhein LD, Fluhr JW,editors. Aging skin: current and future therapeutic strategies. Illinois: Allured Books; 2010.p.19-234.

10. Cao C, Wan S, Jiang Q, et al. All-trans acid attenuates ultraviolet radiation-induced downregulation of aquaporin-3 and water permeability in human keratinocytes.J Cell Physio 2008;215: 506-16.

11. Ji C, Yang Y, Yang B, et al. Trans-zeatin attenuates ultraviolet induced down-regulation of aquaporin-3 in cultured human skin keratinocytes.Int J Mol Med 2010;26:257-63.

12. Bhavna D, Jyoti K. Centella asiatica: the elixir of life. Int J Res Ayurveda Pharm 2011;2:431-8.

13. Gohil KJ, Patel JA, Gajjar AK. Pharmacological review on Centella asiatica: a potential herbal cure-all. Indian J Pharm Sci 2010;72:546-56.

14. Zainol NA, Voo SC, Sarmidi MR, et al. Profiling of Centella asiatica (L.) urban extract. Malaysian J Anal Sci 2008;12:322-7.

15. Lu L, Ying K, Wei S, et al. Asiaticoside induction for cell-cycle progression, proliferation and collagen synthesis in human dermal fibroblasts. Int J Dermatol 2004;43:801-7.

16. Yulianti L, Mardliyati E, Brahmono K, et al. Asiaticoside induces cell proliferation and collagen synthesis in human dermal fibroblasts. Univ Med 2015;34.:96-103.

17. Yulianti L, Brahmono K, Mardliyanti E, et al. Effects of Centella asiatica ethanolic extract encapsulated in chitosan nanoparticles on proliferation activity of skin fibroblasts and keratinocytes, type I and III collagen synthesis 
and aquaporin 3 expression in vitro. J Pharm Biomed Sci 2016;6:315-27.

18. Phaechamud T, Yodkhum K, Charoenteeraboon $\mathrm{J}$, et al. Chitosan-aluminum monostearate composite sponge dressing containing asiaticoside for wound healing and angiogenesis promotion in chronic wound. Mat Sci Eng CMater 2015;50:210-25.

19. Pereda MCV, Dieamant GC, Eberlin S, et al. Effect of green Coffea arabica L. seed oil on extracellular matrix components and waterchannel expression in in vitro and ex vivo human skin models. J Cosmet Dermatol 2009;8:56-62.

20. Pereda MCV, Dieamant GC, Eberlin S, et al. Expression of differential genes involved in the maintenance of water balance in human skin by Piptadenia colubrina extract. J Cosmet Dermatol 2010;9:35-43.

21. Perez C, Dumont S, Cattuzzo L. Cosmetogenomics decodes hydrating action in cells. Personal Care 2013;6:79-82.

22. Verdier-Sevrain S, Bonte F. Skin hydration: A review on its molecular mechanisms. J Cosmet Dermatol 2007;6:75-82.
23. Li J, Tang H, Hu X, Chen M, et al. Aquaporin 3 gene and protein expression in sun-protected human skin decreases with skin ageing. Aus J Dermatol 2010;51:106-12.

24. Boury-Jamot M, Daraspe J, Bonte F, et al. Skin aquaporins: function in hydration, wound healing, and skin epidermis homeostasis. Handb Exp Pharmacol 2009;190:205-17.

25. Hara-Chikuma M, Verkman AS. Roles of aquaporin-3 in the epidermis. J Invest Dermatol 2008;128:2145-51.

26. Hara-Chikuma M, Verkman AS. Aquaporin 3 facilitates epidermal cell migration and proliferation during wound healing. J Mol Med 2007;86:221-31.

27. Yulianti L, Brahmono K, Mardliyanti E, et al. Proceeding ICMTA. In silico molecular modeling and docking studies of aquaporin-3 with active compounds of Centella asiatica. Jakarta: ICMTA; 2013.

28. Bellemere G, Von Stetten O, Oddos T. Retinoic acid increases aquaporin 3 expression in normal human skin. J Invest Dermatol 2008;128:5428. 